\title{
VALIDITAS PERANGKAT PEMBELAJARAN KONSEP PENCEMARAN LINGKUNGAN UNTUK MENINGKATKAN KETERAMPILAN KOMUNIKASI SAINS SISWA SMA DI BANJARMASIN
}

\author{
Istiqamah \\ Program Studi Tadris Biologi Fakultas Tarbiyah dan Keguruan UIN Antasari Banjarmasin \\ Jalan A.Yani Km 4,5 Banjarmasin \\ Email: Istiqamahmr@gmail.com, Hp: 085348827775
}

Website: https://jurnal.uin-antasari.ac.id/index.php/jtjik/index Received: November 2019; Accepted: November 2019; Published: Desember 2019

\begin{abstract}
This research aimed to develop the valid learning tools. They are developed in the form of Syllabus, Lesson Plan ( $L P)$, Student's Worksheet, Teaching Materials, Assessment Sheets, and Learning Media. The type of research is Research \& Development (R\&D) which was developed by using the ASSURE model and analyzed descriptively. Furthermore, R\&D is focused on the validation test process. The final result is to produce the valid development product of learning tools. The level of validity of this research was determined through the stages of expert validation (learning tool experts) and user validation (students). This expert test (validation) has done by 3 expert validators in the field of education, while the user test was carried out by 3 validators which were 3 students of $10^{\text {th }}$ Class of Islamic Highschool of Muhammadiyah 1 Banjamasin based on its students' academic levels to test the readability of Student's Worksheets, Teaching Materials and Cognitive Assessment Sheets (LP-1). The results showed the level of validity of the learning tools from the expert validation is valid. The validation results are $73.33 \%$ in Syllabus (quite valid), $72.37 \%$ in Lesson Plan (valid enough), $72.43 \%$ in Student's Worksheets (valid enough), $73.43 \%$ in Teaching Material (valid enough), and 75\% in Assessment Sheets (valid enough), and 73.2\% in Learning Media (valid enough). The results of user validation are in good categories. Thus, it is concluded that the learning tools are classified as valid.
\end{abstract}

Keywords: Validity Level; Learning Tools; ASSURE Model; Scientific Communication Skills

\begin{abstract}
ABSTRAK
Penelitian ini bertujuan untuk mengembangkan perangkat pembelajaran yang valid. Perangkat pembelajaran yang dikembangkan berupa Silabus, Rencana Pelaksanaan Pembelajaran (RPP), Lembar Kerja Siswa (LKS), Bahan Ajar, Lembar Penilaian, dan Media Pembelajaran. Jenis penelitian ini adalah Research \& Development (R\&D) dan dikembangkan menggunakan model ASSURE serta dianalisis secara deskriptif. Penelitian dan pengembangan ini difokuskan pada proses uji validasi. Hasil akhir dari penelitian ini adalah menghasilkan produk pengembangan perangkat pembelajaran yang valid. Untuk mengetahui tingkat validitas perangkat penelitian ini melalui tahapan validasi ahli (pakar perangkat pembelajaran) dan validasi pengguna (Siswa). Uji ahli (validasi) ini dilakukan oleh 3 validator yang merupakan pakar dibidang pendidikan, sedangkan uji pengguna dilakukan oleh 3 validator yaitu 3 orang siswa kelas X Madrasah Aliyah Muhammadiyah 1 Banjarmasin yang diambil berdasarkan tingkatan akademik siswa untuk menguji keterbacaan LKS, Bahan Ajar dan Lembar Penilaian kognitif (LP-1). Hasil penelitian menunjukkan tingkat validitas perangkat pembelajaran dari validasi ahli adalah valid. Hasil validasi tersebut yaitu silabus 73,33\% (cukup valid), RPP 72,37\%
\end{abstract}


(cukup valid), LKS 72,43\% (cukup valid), Bahan Ajar 73,43\% (cukup valid), dan lembar penilaian 75\% (cukup valid), dan Media Pembelajaran 73,2\% (cukup valid). Hasil validasi pengguna menunjukkan kategori baik.Dengan demikian, maka disimpulkan bahwa perangkat pembelajaran tergolong valid.

Kata kunci: Tingkat Validitas; Perangkat Pembelajaran; Model ASSURE; Keterampilan Komunikasi Sains

\section{PENDAHULUAN}

Biologi merupakan salah satu mata pelajaran yang memegang peranan dalam kehidupan sehari-hari yang disajikan dalam dunia pendidikan. Biologi perlu disajikan sedemikian rupa oleh guru menggunakan perangkat pembelajaran yang valid agar materi mudah dipahami oleh siswa. Berdasarkan wawancara (observasi) dengan guru Biologi kelas $\mathrm{X}$ SMA Muhammadiyah 1 Banjarmasin bahwa beliau masih menggunakan perangkat pembelajaran khususnya pada konsep Pencemaran Lingkungan yang belum mengarah kepada perangkat pembelajaran terbaru (kurikulum 2013), tidak berpusat pada siswa dan belum memaksimalkan nilai akademik dan keterampilan komunikasi sains siswa.

Guru lebih banyak menekankan pada pemberian materi secara langsung berupa ceramah dan tanya jawab hal ini didasarkan pada alasan lebih praktis dan tidak banyak menyita waktu, akibatnya keterampilan komunikasi siswa menjadi kurang karena kurangnya kesempatan siswa untuk menyampaikan informasi dan pengetahuan yang dimilikinya. Menurut Devi (2013) salah satu kunci keberhasilan suatu pendidikan di sekolah adalah keberhasilan guru dalam menyajikan materi pelajaran yang dapat memfasilitasi siswanya untuk mencapai kompetensi yang diharapkan. Setiap kurikulum yang berlaku, diharapkan guru mengembangkan model pembelajarannya sesuai dengan kondisi lapangan, dan tidak hanya 'transfer of knowledge' atau hanya mentransfer ilmu saja.

Berdasarkan hal-hal tersebut maka terjadi adanya kesenjangan antara perangkat pembelajaran yang diharapkan dan pembelajaran yang sekarang guru gunakan. Perangkat pembelajaran yang diharapkan adalah perangkat yang telah mengarahkan pada perangkat pembelajaran kurikulum 2013, valid, pembelajaran yang berpusat pada siswa, dan perangkat pembelajaran yang bukan hanya dapat meningkatkan kemampuan intelektual siswa namun juga keterampilan siswa salah satunya adalah keterampilan komunikasi siswa.

Salah satu materi atau konsep Biologi kelas X SMA/Aliyah adalah Pencemaran Lingkungan. Materi ini merupakan konsep yang memerlukan kegiatan penyelidikan dan penyelesaian masalah mengingat konsep ini banyak memiliki masalah-masalah lingkungan nyata yang sangat baik apabila siswa dapat merasakan atau melihatnya secara langsung. Seperti halnya masalah pencemaran lingkungan pada suara, tanah, udara, dan air, maupun masalah lingkungan seperti penumpukan sampah, pencemaran tambang, pencemaran limbah amoniak, limbah besi tua, dan lain-lain yang ada di tengah masyarakat. Konsep tersebut akan lebih mudah dipahami siswa serta dapat merangsang kemampuan dan keterampilan siswa apabila diterapkan dalam kegiatan pembelajaran yang tepat.

Menurut Rasifirdani pengembangan perangkat pembelajaran adalah serangkaian proses atau kegiatan yang dilakukan untuk menghasilkan suatu perangkat pembelajaran berdsarkan teori pengembangan yang terlah ada. Proses pengembangan perangkat pembelajaran harus mengikuti suatu tahapan tertentu yang disebut model pengembangan perangkat pembelajaran. Model 
pengembangan perangkat pembelajaran sangat banyak contohnya saja ASSURE, ADDIE, model Hanafin and Peck, Dick and Carey, model pengembangan 4D, dan lain-lain. Penulis memilih model pengembangan ASSURE karena model ini lebih diformulasikan untuk kegiatan KBM. Selain model ASSURE, model pengembangan lain yang dapat digunakan yaitu Dick and Carey dan model pengembangan 4D.

Menurut Akbar (2009) bahwa masih banyak guru yang tidak memiliki perangkat pembelajaran saat mengajar. Bahkan yang lebih memprihatinkan bahwa perangkat pembelajaran digunakan hanya sebatas administrasi dan formalitas, dalam artian bahwa sang guru mengaplikasikan sesuatu yang berbeda dari perangkat mengajarnya. Maka dari itu, perlu adanya kegiatan pengembangan perangkat pembelajaran mengingat pentingnya perangkat pembelajaran itu sendiri bagi kegiatan belajar mengajar baik untuk jangka pendek dan jangka penjangnya.

Perangkat pembelajaran yang dihasilkan dapat bermanfaat baik bagi pihak sekolah, guru, dan siswa, maupun bagi masyarakat. Manfaat yang didapat bagi pihak sekolah, guru yaitu sebagai referensi dalam pembuatan perangkat pembelajaran, panduan pembelajaran yang valid dan lebih up to date sesuai dengan perkembangan zaman serta dapat digunakan lagi di kelas kelas berikutnya (tidak sekali pakai). Dengan adanya perangkat pembelajaran yang valid dan sudah diuji, maka diharapkan akan memperbaiki kegiatan belajar mengajar dan berdampak pada peningkatan nilai siswa itu sediri. Selain manfaat yang akan di dapat bagi pihak sekolah, pengembangan perangkat pembelajaran ini juga dapat dimanfaatkan oleh masyarakat sebagai referensi pengembangan perangkat pembelajaran biologi yang valid, praktis dan efisien.

Berdasarkan beberapa uraian di atas disusunlah rumusan masalah yaitu adalah bagaimana mengembangkan perangkat pembelajaran konsep Pencemaran Lingkungan dengan menggunakan model pengembangan ASSURE yang valid yang dapat meningkatkan komunikasi sains siswa SMA. Pengembangan perangkat ini juga bertujuan membantu guru dalam mengembangkan perangkat pembelajaran yang bertitik tolak pada siswa sebagai pembelajar yang bertujuan untuk meningkatkan komunikasi sains siswa dengan judul Tingkat Validitas Perangkat Pembelajaran Konsep Pencemaran Lingkungan Yang Dikembangkan Menggunakan Model Assure Untuk Meningkatkan Keterampilan Komunikasi Sains Siswa SMA.

\section{METODE}

Jenis penelitian ini adalah Research \& Development (R\&D) dan model pengembangan yang digunakan mengacu pada model ASSURE. Model ASSURE ini terdiri dari enam tahap yaitu: (1) analyze learners; (2) state objectives; (3) select methods, media, and materials; (4) utilize material; (5) requires learners participation; dan (6) evaluate and revise.

Penelitian dan pengembangan ini dibatasi hanya sampai menvalidasi perangkat pembelajaran. Penelitian dan pengembangan ini difokuskan pada proses uji validasi yang melalui uji validasi ahli dan isi atau keterbacaan pada uji validasi pengguna pada pengembangan perangkat yang dibuat. Hasil akhir dari penelitian ini adalah menghasilkan produk pengembangan perangkat pembelajaran yang valid.

Pengukuran tingkat validitas perangkat pembelajaran yang telah dikembangkan melalui 2 (dua) tahapan. Tahapan pertama yaitu tahap validasi ahli yang dilakukan oleh 3 (tiga) orang validator (Drs. H. M. Zaini, M. Pd, Amalia Rezeki, M.Pd. dan Ayatussa'adah, M. Pd). Perangkat pembelajaran yang divalidasi oleh validator ahli yaitu Silabus, Rencana Pelaksanaan Pembelajaran (RPP), Lembar Kerja Siswa (LKS), Bahan 
Ajar, Lembar Penilaian, dan Media Pembelajaran.

Perangkat pembelajaran akan diukur secara kategorikal berdasarkan referensi Akbar (2013) yaitu:

a. Sangat valid (85,01-100,00\%),

b. Cukup valid (70,01-85,00\%),

c. Kurang valid $(50,01-70,00 \%)$,

d. Tidak valid (01,00-50,00\%)

Tahap kedua yaitu validasi pengguna yang dilakukan oleh 3 (tiga) orang siswa kelas X Madrasah Aliyah Muhammadiyah 1 Banjarmasin. Validasi ini untuk mengukur keterbacaan siswa terhadap perangkat pembelajaran yang nantinya digunakan berupa bahan ajar, LP-1, dan LKS.

Pada tahap ini akan diukur secara kategorikal sesuai referensi Arikunto dkk (1998) yaitu:

a. Baik (76-100\%),

b. Cukup Baik (56-75\%),

c. Kurang (40-55\%),

d. Tidak Baik $(0<40 \%)$.

Hasil penelitian pengembangan ini adalah perangkat pembelajaran biologi yang meliputi Silabus, Rencana Pelaksanaan Pembelajaran (RPP), Lembar Kerja Siswa (LKS), Bahan Ajar, Lembar Penilaian, dan Media Pembelajaran. Instrumen pengumpulan data yang digunakan yaitu lembar validasi ahli, dan lembar uji validasi pengguna. Teknik analisis data yang digunakan dalam penelitian dan pengembangan ini menggunakan analisis deskriptif.

\section{HASIL DAN PEMBAHASAN HASIL PENELITIAN DAN PEMBAHASAN}

Tingkat validitas perangkat pembelajaran berdasarkan hasil penelitian dan pengembangan yang diperoleh dari validasi ahli dan validasi keterbacaan perangkat atau disebut validasi pengguna. Hasil penelitian disajikan sebagai berikut:

\section{Validasi Ahli (Pakar)}

Validasi ahli dilakukan oleh 3 orang validator yang berkompeten yaitu 1)
Drs. H. M. Zaini, M.Pd merupakan dosen di FKIP Universitas Lambung Mangkurat Program Studi Magister Pendidikan Biologi, 2) Amalia Rezeki, M.Pd. merupakan dosen FKIP Universitas Lambung Mangkurat Program Studi Pendidikan Biologi, dan 3) Ayatussa'adah, M. Pd merupakan dosen IAIN Palangkaraya Program Studi Pendidikan Biologi. Hasil validasi ahli selanjutnya digunakan untuk mengukur validitas perangkat pembelajaran. Hasil validasi ahli disajikan pada Tabel 1.

Tabel 1. Hasil Validasi Ahli

\begin{tabular}{|c|c|c|c|}
\hline No & $\begin{array}{l}\text { Perangkat } \\
\text { Pembelajaran }\end{array}$ & $\%$ & $\begin{array}{l}\text { Kriteria } \\
\text { Skor }\end{array}$ \\
\hline 1 & Silabus & 73,33 & Cukup valid \\
\hline 2 & RPP & 72,37 & Cukup valid \\
\hline 3 & LKS & 72,43 & Cukup valid \\
\hline 4 & LP-1 (Produk) & 75 & Cukup valid \\
\hline 5 & LP-2 (Proses) & 75 & Cukup valid \\
\hline 6 & $\begin{array}{l}\text { LP-3 } \\
\text { (Psikomotor) }\end{array}$ & 75 & Cukup valid \\
\hline 7 & $\begin{array}{l}\text { LP-6 (Produk } \\
\text { atau Karya) }\end{array}$ & 75 & Cukup valid \\
\hline 8 & $\begin{array}{l}\text { LP-7 } \\
\text { (Keterampilan } \\
\text { Komukasi } \\
\text { Sains) }\end{array}$ & 75 & Cukup valid \\
\hline 8 & Bahan ajar & 73,43 & Cukup valid \\
\hline 9 & $\begin{array}{l}\text { Media } \\
\text { pembelajaran }\end{array}$ & 73,20 & Cukup valid \\
\hline
\end{tabular}

Kriteria: sangat valid (85,01-100,00\%), cukup valid (70,01-85,00\%), kurang valid (50,01$70,00 \%)$ dan tidak valid (01,00-50,00\%) (Akbar, 2013)

Berdasarkan Tabel 1 diketahui bahwa tingkat validitas perangkat pembelajaran tergolong kategori valid karena hasil validasi seluruh perangkat pembelajaran adalah cukup valid sehingga perangkat pembelajaran yang telah dikembangkan sudah bisa digunakan namun perlu direvisi terlebih dahulu sesuai saran dari validator. Hasil revisi perangkat pembelajaran selanjutnya digunakan pada uji validasi pengguna.

Tingkat validitas perangkat pembelajaran menurut hasil analisis validasi ahli menunjukkan bahwa seluruh perangkat pembelajaran yang divalidasi 
meliputi silabus, RPP, LKS, Lembar Penilaian (LP), bahan ajar, dan media pembelajaran tergolong kategori cukup valid sehingga dapat digunakan pada pembelajaran berdasarkan kriteria yang ditetapkan oleh Akbar (2013). Tati, dkk (2009) bahwa perangkat dikatakan valid jika penilaian ahli menunjukkan bahwa pengembangan perangkat tersebut dilandasi oleh teori yang kuat dan memiliki konsistensi internal, yakni ada keterkaitan komponen dengan perangkat. Hal tersebut menegaskan bahwa validitas merupakan salah satu kriteria yang menentukan kualitas dari suatu produk.

Saran-saran yang diberikan oleh validator antara lain pembuatan silabus dan RPP lebih sistematis, memperbaiki penulisan dan kekurangan pada silabus dan RPP, penambahan indikator proses dan gambar ilustrasi yang menarik pada LKS, materi yang disajikan pada bahan ajar disesuaikan dengan kebutuhan pada LKS, menambah kotak eksperimen dan kotak kosa kata pada bahan ajar, menambahkan gambar dan ilustrasi menarik pada bahan ajar, dan tes atau penilaian produk menggunakan soal berupa essai dan berupa soal produk. Saran-saran tersebut menjadi bahan pertimbangan untuk melakukan revisi.

\section{Validasi Pengguna (Siswa)}

Uji validasi pengguna dilakukan kepada 3 (tiga) orang siswa kelas $\mathrm{X}$ Madrasah Aliyah Muhammadiyah 1 Banjarmasin yang memiliki tingkat kemampuan akademik yang berbeda yaitu tinggi, sedang, dan rendah. 3 (tiga) orang siswa ini dipilih berdasarkan saran oleh guru pengampu mata pelajaran biologi. Uji validasi ini untuk mengukur keterbacaan, ketepatan kata, tampilan bahan ajar, kejelasan makna kalimat dan lain-lain pada perangkat pembelajaran yang nantinya akan digunakan oleh siswa.

Aspek penilaiannya meliputi keterbacaan dari segi pengetikan, pemilihan kata, pemilihan gambar, tampilan bahan ajar, dan menvalidasi kata atau kalimat yang tidak jelas. Perangkat pembelajaran tersebut adalah bahan ajar, LKS, dan lembar penilaian kognitif (LP1). Hasil uji keterbacaan siswa selanjutnya digunakan untuk mengukur validasi perangkat pembelajaran berdasarkan validasi pengguna. Hasil validasi pengguna disajikan pada Tabel 2.

Tabel 2. Hasil validasi pengguna

\begin{tabular}{lcl}
\hline $\begin{array}{l}\text { Perangkat } \\
\text { pembelajaran }\end{array}$ & $\%$ & Kategori \\
\hline Bahan ajar & 95,24 & Baik \\
LKS & 100 & Baik \\
LP-1 Produk & 100 & Baik \\
\hline
\end{tabular}

Sumber: hasil olah data

Keterangan: Baik (76-100\%), Cukup Baik (56$75 \%)$, Kurang (40-55\%), dan Tidak Baik (0< 40\%) (Arikunto dkk, 1998).

\section{Berdasarkan Tabel 2 diketahui} bahwa tingkat validitas perangkat pembelajaran berupa bahan ajar, LKS, dan Lembar Penilaian Kognitif (LP-1) adalah Baik dan layak digunakan setelah dilakukan revisi kecil.

Hasil analisis penelitian dan pengembangan perangkat pembelajaran menunjukkan bahwa tingkat validitas perangkat pembelajaran menurut hasil validasi ahli yaitu cukup valid dan validasi pengguna yaitu baik.

Hasil analisis tingkat validitas perangkat dari uji validasi pengguna menunjukkan bahwa perangkat pembelajaran yang divalidasi pengguna berupa bahan ajar, LKS, dan LP-1 adalah baik. Hal ini dapat disimpulkan bahwa perangkat pembelajaran berupa bahan ajar, LKS, dan LP-1 yang divalidasi memiliki keterbacaan yang baik dan penampilan yang menarik serta mudah dipahami baik ilustrasi, kalimat maupun gambar yang disajikan. Namun ada beberapa hal yang perlu direvisi terlebih dahulu sebelum digunakan, antara lain menambahkan kotak kosakata agar kata yang kurang dimengerti dapat mudah dicari maknanya. Kemudian memperbanyak gambar pada bahan ajar 
agar lebih menarik sesuai saran dari validator.

Uji validasi pengguna dapat pula disebut uji perorangan yang tujuannya untuk memperbaiki keterbacaan pada perangkat baik dari segi pengetikan, pemilihan kata, dan gambar maupun kalimat yang tidak jelas. Hal ini sesuai dengan Nur (2011) yang menyatakan bahwa tujuan uji perorangan yaitu untuk memperbaiki kesalahan ketik, kalimat tidak jelas, petunjuk yang hilang atau tidak jelas, contoh yang tidak sesuai, kosa kata yang tidak dikenal, salah gambar atau halaman, dan gambar yang tidak komunikatif.

Menurut Plomp, dkk (2013) salah satu kriteria produk atau intervensi yang berkualitas tinggi yaitu adalah kevalidan. Suatu desain intervensi atau produk khususnya pengembangan perangkat pembelajaran akan bertambah kuat apabila telah divalidasi. Sehingga kualitas perangkat pembelajaran tersebut tidak diragukan lagi. Menurut Sugiyono (2015) validitas dan realiabilitas instrumen penelitian merupakan hal yang utama dalam meningkatkan efektivitas proses pengumpulan data. Dengan menggunakan instrumen yang valid maka diharapkan akan diperoleh hasil data penelitian yang valid juga. Menurut Tati, dkk (2009) bahwa perangkat dikatakan valid jika penilaian ahli menunjukkan bahwa pengambangan perangkat tersebut dilandasi oleh teori yang kuat dan memiliki konsistensi internal, yakni ada keterkaitan komponen dengan perangkat. Sejalan dengan Akbar (2013) yang menyatakan bahwa perangkat pembelajaran dapat dikatakan valid jika perangkat tersebut memiliki kesesuaian dengan landasan teoritik pengembangannya dan jika digunakan maka dapat mengukur kemampuan yang diharapkan. Menurut Sugiyono (2015) untuk menguji validitas dapat digunakan pendapat ahli (expert judgment). Para ahli diminta pendapatnya tentang instrument yang telah disusun tersebut.
Pengembangan

Perangkat pembelajaran yang telah divalidasi ini diharapkan dapat meningkatkan bukan hanya dari segi kognitif, afektif, dan psikomotor siswa namun juga dari segi keterampilan khususnya keterampilan komunikasi sains siswa. Hal ini dikarenakan Perangkat pembelajaran yang telah dikembangkan dilengkapi oleh RPP yang menggunakan model pembelajaran PBM (pembelajaran berdasarkan masalah). Menurut Arends (2008), Suprihatiningrum (2012) dan Nur (2011) bahwa salah satu keuntungan yang akan didapat pada pembelajaran dengan menggunakan model PBM adalah adanya peningkatan dalam berkomunikasi.

Selain RPP, perangkat pembelajaran yang dikembangkan ini juga menggunakan Lembar Penilaian Produk atau Karya (LP-6) dan Lembar Penilaian Keterampilan Komukasi Sains (LP-7) yang khusus untuk mengukur produk dan keterampilan siswa dalam hal komunikasi sains baik secara tertulis maupun lisan. Hal ini dikarenakan dalam pembelajaran $80 \%$ kegiatannya adalah komunikasi, baik komunikasi secara lisan maupun tertulis. Dengan menggunakan perangkat ini diharapkan dapat memaksimalkan hasil belajar (kognitif, afektif, dan psikomotor) dan keterampilan komukasi sains siswa khususnya pada mata pelajaran biologi. Menurut Devi (2013) salah satu tujuan pembelajaran pada standar kompetensi mata pelajaran IPA adalah melakukan kegiatan ilmiah untuk menumbuhkan kemampuan berpikir, bersikap dan bertindak ilmiah serta berkomunikasi.

\section{PENUTUP}

Simpulan penelitian ini adalah bahwa tingkat validasi perangkat pembelajaran yang telah dikembangkan tergolong valid. Hal ini dilihat dari tingkat validasi ahli yaitu tergolong cukup valid dan hasil validasi pengguna yaitu kategori baik.

Peneliti mengemukakan beberapa saran yaitu: 
1. Perlu dilakukan penelitian lanjutan yang untuk menguji keefektifan dan kepraktisan perangkat pembelajaran ini.

2. Melakukan pengembangan perangkat pembelajaran serupa dengan penelitian ini, namun penilaiannya dilakukan secara individual terutama pada kinerja proses, psikomotor dan keterampilan komunikasi sains agar penilaian siswa dapat lebih objektif.

\section{DAFTAR PUSTAKA}

Akbar, S. 2009. Penelitian Tindakan Kelas (Filosofi, Metodologi, dan Implementasinya). Surya Pena Gemilang. Malang

Akbar, S. 2013. Instrumen Perangkat Pembelajaran. Rosda. Universitas Negeri Malang

Aminah, Neneng. 2014. Analisis Validasi Pengembangan Perangkat Pembelajaran Matematika Dengan Model Plomp Pada Materi Geometri. Universitas Swadaya Gunung Jati Cirebon. Cirebon

Arends. R.I. 2008. Learning to Teach Belajar untuk Mengajar. Pustaka Pelajar

Budiarso, Aris Singgih. 2017. Analisis Validitas Perangkat Pembelajaran Fisika Model Inkuiri Terbimbing untuk Meningkatkan Hasil Belajar Siswa SMA pada Materi Listrik Dinamis (The Analysis Validity of Physics Learning Device Guided Inquiry Model to Improve Student Learning Outcomes SMA on Dynamic Electrical Materials). Universitas Jember (UNEJ)

https://jurnal.unej.ac.id/index.php /JEUJ/article/download/5204/393
4/. Diakses tanggal 15 November 2019

Depdiknas. 2008. Panduan Umum Pengembangan Bahan Ajar. Jakarta: Direktorat Jenderal Manajemen Pendidikan Dasar dan Menengah. (Online),(http://akhmadsudrajat.fi les. wordpress.com/2008/09/panduan -pengembanganbahanajar.pdf), diakses 15 November 2019

Dewi, K., Sadia, I. W., Ristiati, N.P. 2013. Pengembangan Perangkat Pembelajaran Ipa Terpadu dengan Setting Inkuiri Terbimbing untuk Meningkatkan Pemahaman Konsep dan Kinerja Ilmiah Siswa. e-Journal Program Pascasarjana Universitas Pendidikan Ganesha Program Studi Pendidikan IPA (Online), 3 (1): 2013, (http://pasca.undiksha.ac.id/ejournal/index.php/jurnal_ipa/artic le/view/ 548), diakses 15 November 2019.

Devi, P.K. 2013. Keterampilan Proses dalam Pembelajaran IPA. Better Education through Reformed Management and Universal Theacher Upgrading/Pusat Pengembangan dan Pemberdayaan Pendidikan dan Tenaga Kependidikan Ilmu Pengetahuan Alam (PPPPTK IPA). Bandung

Ni'mah, Saidatun, dkk. 2018. Pengembangan Dan Uji Validasi Perangkat Pembelajaran SMA Berbasis Kurikulum 2013 Pada Konsep Sistem Pencernaan. Program Studi Pendidikan Biologi STKIP PGRI Banjarmasin. Banjarmasin 
Nur, M. 2011. Model Pembelajaran Berdasarkan Masalah. Surabaya. Pusat Sains dan Matematika Sekolah UNESA

Plomp, Tjeerd \& Nienke Nieveen. 2013. Educational Design Reasearch. SLO Netherlands Institute for Curiculum Development. http://downloads.slo.nl/Documen ten/educational-design-researchpart-a.pdf diakses 1 April 2019

Rasifirdani. 2013. Berbagai Model Perangkat Pembelajaran. http://rasifirdani.blogspot.com/20 13/03/berbagai-modelpengembangan-perangkat.html diakses tanggal 15 November 2019

Sugiyono. 2015. Metode Penelitian Tindakan Komprehensif. Alfabeta. Yogtakarta

Suprihatiningrum, J. 2012. Strategi Pembelajaran Teori \& Aplikasi. Ar-Ruzz Media. Yogyakarta

Tati, Zulkardi, \& Yusuf Hartono. 2009. Pengembangan Perangkat Pembelajaran Berbasis Kontekstual Pokok Bahasan Turunan di Madrasah Aliyah Negeri 3 Palembang. www.eprints.unsri.ac.id, pdf diakses 1 April 2019

Yusup, Febrianawati. 2018. Uji Validitas dan Reliabilitas Instrumen Penelitian Kuantitatif. Jurnal Ilmiah Kependidikan Fakultas Tarbiyah. https://jurnal.uin.antasari.ac.id. Vol 7, No 1 (2018) 